\title{
INFLUENCE OF COLLECTION FREQUENCY ON POST-IRRADIATION SPERM OUTPUT BY RABBITS*
}

\author{
A. F. MaFEE, J. R. EBLEN AND P. R. WELCH $\dagger$ \\ Agricultural Research Laboratory of The University of Tennessee, Oak Ridge, Tennessee $\$$
}

(Received 11th October 1965)

In order to study the effect of irradiation on testicular function it is important to know the frequency with which ejaculates must be taken to establish accurately the post-irradiation pattern of sperm output. The interval from irradiation to the onset of sterility in mice is said to be unaffected by varying the frequency of mating (Bateman, 1958). ${ }^{32}$ Phosphorus-labelled spermatozoa appear in the ejaculate of bulls at approximately the same time whether they are collected two to three times a day or once a week (Koefoed-Johnsen, 1960). On the other hand, Cox \& Willham (1961) found that irradiated boars reached their minimum sperm output some 12 days later when collected once a week than when collected three times a week, although the pattern of recovery in sperm production was not altered.

The current work was conducted to determine whether or not an increased frequency of collection yielded more reliable results than the once-a-week practice normally employed in our laboratory. One ejaculate a week undoubtedly allows replenishment of epididymal sperm reserves between collections. We found very little increase in total sperm output during 3-week collection periods when two ejaculates were taken every 2nd day rather than every 3rd day, leading to the conclusion that two ejaculates taken every other day harvested spermatozoa as fast as they were produced. Six litter-mate pairs of male Dutch rabbits were utilized with one member of each pair being randomly assigned to each of the two groups. Epididymal sperm reserves were lowered in the everyother-day group by the collection of seven ejaculates from each male during 1 day. The following day a 600-r dose of $\gamma$-radiation was administered to the testes of all males. On the day following irradiation, a single ejaculate was taken from each male in Group I and two ejaculates from those in Group II. During the ensuing 16 weeks one ejaculate a week was obtained from males in Group I while two ejaculates, approximately $30 \mathrm{~min}$ apart, were taken every 2nd day from those in Group II. The volume of each ejaculate was determined after removal of the coagulum and sperm concentration was determined by haemocytometer count.

\footnotetext{
* This manuscript is published with the permission of the Director of the University of Tennessee Agricultural Experiment Station, Knoxville.

$\dagger$ Present address: Loveland Division, Hewlett-Packard Corp., Loveland, Colorado.

$\ddagger$ Operated by the Tennessee Agricultural Experiment Station for the U.S. Atomic Energy Commission under Contract No. AT-40-1-GEN-242.
} 
Sperm output by the two groups of males during the first 57 days postirradiation is shown in Text-fig. 1. The data are plotted as average total spermatozoa/collection day for the six males in each group; thus, the values for Group I are averages of six ejaculates at each point while those for Group II are means of the total from six pairs of ejaculates, i.e. means of twelve collections. The data indicate that increasing the frequency of collection beyond once a week offers little opportunity for detecting irradiation damage any earlier in the post-exposure period. Although the level of minimum sperm output was reached a few days earlier as a result of more frequent collection, the decline

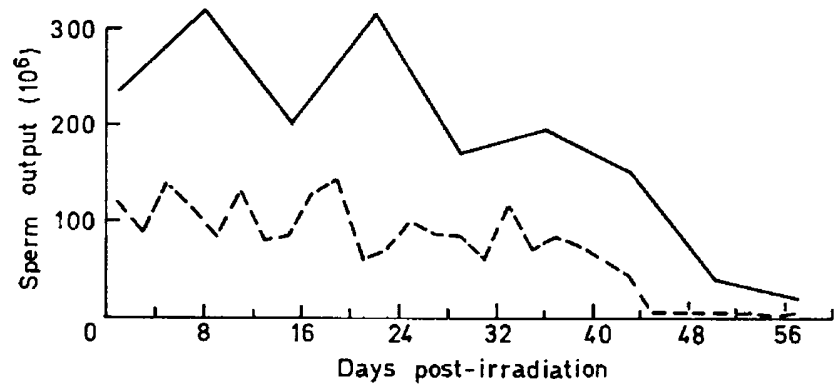

TEXT-FIG. 1. Early post-irradiation sperm output by rabbits on different collection frequencies. Average number of spermatozoa per ejaculate (Group I, -) or per pair of ejaculates (Group II, . . - - (see text).

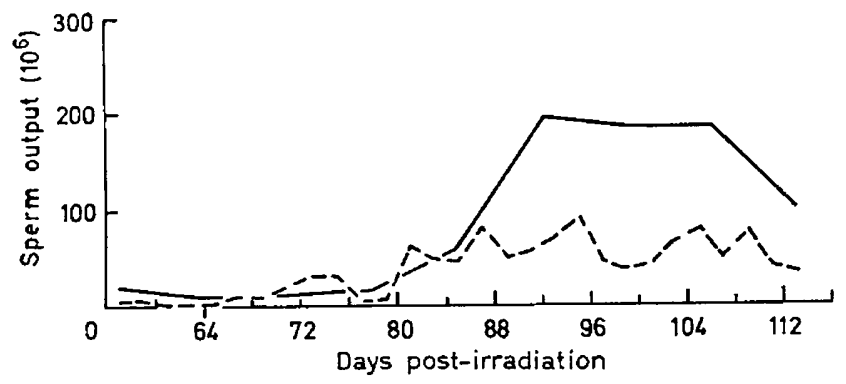

TEXT-FIG. 2. Sperm output during the 'recovery period' by rabbits on different collection frequencies. (See caption to Text-fig. 1).

began at approximately the same time and proceeded at similar rates in the two groups. The 2-day group approached azoospermia a few days earlier but this was to be expected since their more frequent collection prevented the build-up of epididymal sperm reserves. The average sperm production on each day of collection was higher for the one ejaculate a week animals. However, when total sperm output for the first 5 weeks post-irradiation was calculated, the more frequently collected animals had produced 1.2 times more spermatozoa. Among those males collected twice every other day the first ejaculates averaged $43.1 \times 10^{6}$ spermatozoa while the second averaged $59.5 \times 10^{6}$. This can be explained only by assuming that the manipulations of the first collection acted as a stimulus for increased sperm output in the second ejaculate.

It is also evident from Text-fig. 2 that more frequent collection offers no appreciable advantage in establishing the rate of recovery of sperm production 
by irradiated animals. If one is interested in obtaining the maximum number of spermatozoa from test animals in a given period or in closely following dayto-day changes, then more frequent collections are desirable. In most experiments, however, the interest is in delineating somewhat wider patterns of response, in which case weekly semen collections would be adequate.

\section{REFERENCES}

Bateman, A. J. (1958) Mutagenic sensitivity of maturing germ cells in the male mouse. Heredity, 12, 213.

Cox, D. F. \& Willham, R. L. (1961) Influences on the patterns of sperm production in swine following $\mathrm{X}$-irradiation. F. exp. Zool. 146, 5.

KOEFOED-Johnsen, H. H. (1960) Influence of ejaculation frequency on the time required for sperm formation and epididymal passage in the bull. Nature, Lond. 185, 49. 